\title{
Typology of adults diagnosed with mental disorders based on socio-demographics and clinical and service use characteristics
}

\author{
Marie-Josée Fleury ${ }^{1,2^{*}}$, Guy Grenier ${ }^{2}$, Jean-Marie Bamvita ${ }^{2}$, Michel Perreault ${ }^{1,2}$ and Jean-Caron ${ }^{1,2}$
}

\begin{abstract}
Background: Mental disorder is a leading cause of morbidity worldwide. Its cost and negative impact on productivity are substantial. Consequently, improving mental health-care system efficiency - especially service utilisation - is a priority. Few studies have explored the use of services by specific subgroups of persons with mental disorder; a better understanding of these individuals is key to improving service planning. This study develops a typology of individuals, diagnosed with mental disorder in a 12-month period, based on their individual characteristics and use of services within a Canadian urban catchment area of 258,000 persons served by a psychiatric hospital.

Methods: From among the 2,443 people who took part in the survey, 406 (17\%) experienced at least one episode of mental disorder (as per the Composite International Diagnostic Interview (CIDI)) in the 12 months pre-interview. These individuals were selected for cluster analysis.

Results: Analysis yielded four user clusters: people who experienced mainly anxiety disorder; depressive disorder; alcohol and/or drug disorder; and multiple mental and dependence disorder. Two clusters were more closely associated with females and anxiety or depressive disorders. In the two other clusters, males were over-represented compared with the sample as a whole, namely, substance abuses with or without concomitant mental disorder. Clusters with the greatest number of mental disorders per subject used a greater number of mental health-care services. Conversely, clusters associated exclusively with dependence disorders used few services.

Conclusion: The study found considerable heterogeneity among socio-demographic characteristics, number of disorders, and number of health-care services used by individuals with mental or dependence disorders. Cluster analysis revealed important differences in service use with regard to gender and age. It reinforces the relevance of developing targeted programs for subgroups of individuals with mental and/or dependence disorders. Strategies aimed at changing low service users' attitude (youths and males) or instituting specialised programs for that particular clientele should be promoted. Finally, as concomitant disorders are frequent among individuals with mental disorder, psychological services and/or addiction programs must be prioritised as components of integrated services when planning treatment.
\end{abstract}

\section{Background}

Mental disorder is one of the leading causes of morbidity worldwide. Its cost and negative impact on productivity are substantial. Consequently, improving mental health-care system efficiency - especially service utilisation - is a priority. A systematic literature review reveals

\footnotetext{
* Correspondence: flemar@douglas.mcgill.ca

'Department of Psychiatry, McGill University, 845 Sherbrooke Street West, Montreal, Quebec, Canada, H3A 2T5

Full list of author information is available at the end of the article
}

that prevalence rates at 12 months and lifetime are as follows: $10.6 \%$ and $16.6 \%$, respectively, for anxiety disorders [1]; $4.1 \%$ and $6.7 \%$ for major depressive disorders [2]; $6.6 \%$ and $13.2 \%$ for alcohol use disorders; and $2.4 \%$ both in the case of drug use disorders [3]. Mental disorders are frequently associated with alcohol or drug use disorders. The U.S. National Comorbidity Surveys evaluated that $42.7 \%$ of respondents with alcohol or drug disorder also had a mental disorder in the 12 previous
C Biomed Central 
months, and $14.7 \%$ a mental disorder along with alcohol or drug disorder [4].

Risk factors and correlates to mental or substance use disorders have also been extensively investigated [5-8]. Age, gender, income, and marital and employment status are the principal socio-demographic factors associated with the presence of mental disorder. Being female, middle-aged, widowed, separated or divorced and a low-income earner increases the risk of major depressive disorder [6]. A systematic literature review showed that anxiety disorders were approximately twice as prevalent among females [1]. For substance use disorders, studies reveal a generally greater prevalence among males and youths [3].

Mental health-care service use has also been the subject of many epidemiological studies. The most frequently used model for identifying factors associated with service use is Andersen's behavioural model which classifies predictors of service use into three categories: predisposing, enabling, and needs-related factors [9]. Predisposing factors are individual characteristics that existed prior to the illness such as age, gender, language, marital status, race/ethnicity, and country of birth. Several studies have found that people aged 25 to 44 [10-12], females [10-17], previously married $[12,15,16,18,19]$, highly educated $[18,20]$, white $[11,15,21]$, and native-born $[22,23]$ are most likely to use health-care services. Enabling factors refer to features that influence care delivery and attitudes toward care; they encompass variables such as income, social support, and geographical location. The most important enabling factor is income. People with more elevated socio-economic status tend to use psychiatric and psychological care more assiduously, even among individuals with the same insurance coverage [20,24-26]. Finally, needs-related factors include assessments of physical and mental health by patients and professionals, including diagnosis, severity of the disorder, and perceived needs. Depressive disorders [20] and anxiety, particularly panic disorders $[27,28]$ are strong predictors of health service use.

Utilisation of services has also been studied with regard to the use of primary mental health-care (e.g. general practitioners) or specialised mental health-care (e.g. psychiatrists). Individuals who use primary care are mainly female, older, more highly educated, live with a spouse or partner, and generally have anxiety or depressive disorders [29]. Conversely, frequent users of psychiatric services (second- or third-line services) are generally male, young or middle-aged, unemployed, live alone, have low social support and, often, a dual diagnosis of mental and substance use disorder [13,30,31]. Finally, youths and people with substance use disorders only use few health-care services $[32,33]$.
DSM-IV, the most widely recognised mental health classification system, provides a detailed clinical profile of mental disorder; however, its use in forecasting needs or health-care service utilisation is limited [34]. An alternative classification suggests that mental health-care users can be described in terms of clusters based on several characteristics. With the use of clusters, persons may be considered in broad terms; in addition, subgroups may be correlated with clinical and socio-demographic variables and patterns of service use [34].

Cluster analysis has mainly been used to create typologies of patients with serious mental disorders [34]. Studies have identified frequent users of in-patient services $[35,36]$, patients with schizophrenia treated in the community [37], patients with serious mental illness according to their level of functioning [38], patients with dual diagnoses of serious mental disorders and substance use [39] first-ever admitted psychiatric in-patients [40]. Very few studies have explored subgroups of individuals with common mental disorders. An exception is a study by Mitchell and colleagues [41] that used cluster analysis to classify adults with problematic online experiences and conventional problems (mental and physical health problems; family and/or other relationship problems; victimisation; aggressive behaviour) from a clinical perspective. Identifying individuals with common sociodemographic and clinical characteristics and patterns of service use, however, is essential to the efficacious planning of mental health-care delivery [38].

In an effort to enhance knowledge of service needs profiling, this Canadian urban catchment area study (258,000 persons served by a psychiatric hospital) includes a typology of individuals diagnosed with mental disorder in a 12-month period based on their individual characteristics and use of services. Variables used in the cluster analysis are based on Andersen's behavioural model [9], which considers that health-care service use is determined by predisposing, enabling, and needsrelated factors.

\section{Methods}

\section{Design and study population}

The study focuses on an epidemiologic catchment area in the south-western section of Montreal, Canada. This area has a population of 258,000 and encompasses a broad range of social structures, socio-economic status, education, availability of health-care services, neighbourhood dynamics, and levels of security [42].

The catchment area includes six neighbourhoods, ranging in population from 23,205 to 90,640. Immigrants represent $25 \%$ of the population (versus $26 \%$ in Montreal). The proportion of low-income household represents 33\% (versus 23\% in the province of Quebec and $35 \%$ in Montreal). Low-income households are located 
mainly in two of the six neighbourhoods where close to half of the residents are low-income earners. Mental health-care services are chiefly delivered by three organisations: two health and social service centres (created through the merger of a general hospital, community local service centres, and nursing homes) that provide primary and specialised health-care services; and a psychiatric hospital that delivers specialised care (i.e. second- and third-line services). Sixteen community-based agencies (voluntary sector) offering primary mental health-care services are also present; they provide numerous services (e.g. crisis centre, day centres, selfhelp groups, back-to-work programs) to people with mental disorder or their relatives. General practitioners and psychologists practising in private clinics complete the primary mental health-care system in this area.

\section{Selection criteria and sample}

To be included in the survey, participants had to be aged 15 to 65 and reside in the study area. The sampling was equally distributed in the study area among the various neighbourhoods [42]. The discrepancy between the study population and the sample has been readjusted as regards age and gender distribution by allocating a thoroughly calculated weight to each participant.

Interviews were conducted at home using portable computers. Only one person per target household was selected using procedures and criteria contained in the National Population Health Survey (NPHS, 2003-2005). Participants had the option to choose the language (English or French) of their interview. The research was approved by the Douglas Hospital Research Ethics Board Committee. Data were collected in a random sample of the catchment area from June to December 2009 by specially trained interviewers. Each participant was required to sign a consent form before answering the questionnaire. For those aged 15 to 17, parents had to give authorization before the interview.

A randomly selected sample of 2,433 individuals took part in the survey. The mean age of the sample was 42.4 (SD: 13.3). Sixty-three percent were female. After weighting for age and gender, the mean age of the sample was 40.7 (SD: 14.1) and the proportion of females was $52 \%$. Forty-five percent were married or common law versus $17 \%$ divorced or separated and $37 \%$ single. Seventy-two percent completed post-secondary education and $77 \%$ held a job in the last 12 months. French was the first language for $54 \%$ of participants and English for 22\%. Eighty-two percent were Caucasian; 24\% were non-European immigrants. Average personal income was CA $\$ 28,688$ (SD: 31,061) and average household income, CA $\$ 49,566$ (SD: 51,057). A full description of the study has been published [42].

\section{Variables, measurement instruments and data collection} Variables assessed in the descriptive analysis (and, in part, in the cluster analysis) are displayed in Table 1. Variables are categorised according to Andersen's behavioural model for predisposing factors, enabling factors, and needs-related factors and health-service utilisation [9]. According to the literature, the most influential predisposing factors are age, gender, marital status, household size, and education. Also included among predisposing factors

Table 1 Variables assessed in the study

\begin{tabular}{|c|c|c|c|}
\hline \multicolumn{3}{|c|}{ Variables } & Measuring Instruments \\
\hline \multirow[t]{7}{*}{ Predisposing factors } & $\begin{array}{l}\text { Socio-demographic } \\
\text { variables }^{1}\end{array}$ & Age & \\
\hline & & Gender & \\
\hline & & Marital status & \\
\hline & & Household size & CCHS 1.2 (Statistics Canada 2001) $^{a}$ \\
\hline & & Education & \\
\hline & & First language & \\
\hline & & Country of birth & \\
\hline Enabling factors & Economic factors $^{1}$ & $\begin{array}{l}\text { Income (household; main } \\
\text { source) }\end{array}$ & CCHS 1.2 (Statistics Canada 2001) \\
\hline \multirow[t]{3}{*}{ Needs-related factors } & \multirow{2}{*}{\multicolumn{2}{|c|}{ Mental disorders (type and number) }} & $\begin{array}{l}\text { Composite International Diagnostic Interview (CIDI), (Statistics } \\
\text { Canada 2000) }\end{array}$ \\
\hline & & & Drug Abuse Screening Test (DAST) ${ }^{a}$ \\
\hline & \multicolumn{2}{|c|}{ Psychological distress ${ }^{5}$} & Alcohol Use Disorders Identification Test (AUDIT) ${ }^{a}$ \\
\hline \multirow[t]{2}{*}{$\begin{array}{l}\text { Health-service } \\
\text { utilisation }\end{array}$} & \multicolumn{3}{|c|}{$\begin{array}{l}\text { Services provided in hospitals (including hospitalisation), mental health centres, rehabilitation centres, private clinics, } \\
\text { pharmacies, and in the voluntary sector (e.g. support groups, crisis-line services). }\end{array}$} \\
\hline & \multicolumn{3}{|c|}{$\begin{array}{c}\text { Professionals consulted: psychologists, general practitioners, psychiatrists, case managers, toxicologists, nurses, social workers, } \\
\text { psychotherapists, pharmacists, other health professionals. }\end{array}$} \\
\hline
\end{tabular}

\footnotetext{
${ }^{a}$ Measurement instruments validated in the French-speaking population
} 
in this study were first language and country of birth, since linguistic or cultural differences can be barriers to healthservice access. The most important enabling factor is income (household and main source). Needs-related factors include type and number of mental disorders and psychological distress. Finally, health-service utilisation includes services provided according to types of organisation (i.e. primary or specialized care) and professionals consulted (e.g. psychiatrists, psychologists, and general practitioners).

Many instruments were used to measure specific health and psychosocial parameters. Mental health diagnostics are based on the Composite International Diagnostic Interview (CIDI), an instrument created by a WHO working group [43]. CIDI diagnoses, based on DSM-IV, include anxiety disorders (e.g. agoraphobia, social phobia, panic disorder), mood disorders (major depression, mania) and substance-use disorders (alcohol and drug abuse and dependence). Since its development in 1990, the CIDI has been used in several large-scale community epidemiological surveys throughout the world [43-46]. Substance abuse level was measured with the Drug Abuse Screening Test (DAST), a 20-item (yes/ no) measure of past-year drug use [47]. Alcohol use level was assessed with the Alcohol Use Disorders Identification Test (AUDIT), a ten-item questionnaire (yes/ no) measuring the degree of dependence and high-risk alcohol consumption [48]. Psychological distress was measured with the k-10 psychological Distress Scale [49], which contains 10 questions assessing the frequencies of previous recent psychological distress on 5-point Likert scale [50]. Socio-demographic and economic data were collected using the Canadian Community Health Survey questionnaire (CCHS 1.2). The questionnaire on mental health service use was adapted from CCHS 1.2. Participants who were identified with mental or emotional problems were invited to indicate the services they used, type and frequency of utilisation, and degree of appropriateness of the service they used. Services covered by this questionnaire were those offered in hospitals (including hospitalisation), mental health local community service centres, rehabilitation centres, private clinics, pharmacies and by the voluntary sector (e.g. support groups, crisis line services), including the following professionals: psychiatrists, psychologists, general practitioners, case managers, toxicologists, nurses, psychotherapists, pharmacists and other health professionals. All of these instruments were validated among the French-speaking population.

\section{Analyses}

Frequency distributions were calculated for categorical variables. For continuous variables, mean values and their standard deviations were generated. Eleven variables were selected for cluster analysis, based on their impact on service use and the potential to characterise user profiles. The clustering of participants, based on individuals who were diagnosed with mental disorders, was computed using SPSS Statistics 17.0. The only multi-categorical qualitative variable was 'age'. Other categorical variables were: gender, alcohol dependence, drug dependence, anxiety (panic disorder, agoraphobia, social phobia), major depressive disorder, and mania. Continuous variables were: household income, psychological distress score, number of mental disorders per subject, and number of health services used. Categorical variables were entered first, followed by continuous variables. To determine inter-subject distance, the Log-likelihood method was employed. Participants' classification was made using the Schwarz-Bayesian criteria. The final number of clusters was automatically determined according to their overall contribution to inter-class homogeneity.

\section{Results}

Description of the sample: predisposing, enabling and needs factors

Among the 2,433 people who took part in the survey, 406 (17\%) experienced at least one episode of mental disorder in the 12 months pre-interview according to the Composite International Diagnostic Interview (CIDI) and were selected for the analyses described below. The sample was representative of the source population. The distribution characteristics of participants who were diagnosed with mental disorder are displayed in Table 2. With respect to predisposing factors, the sample consisted of $56 \%$ females. The mean age was 39.4 years (SD: 13.1). Eighty-one percent reported Canada as their country of birth. Most participants (51\%) were single or never legally married. Regarding enabling factors, a large minority of participants (45\%) earned a salary as their main source of income. Thirteen percent reported receiving social welfare, and 3\% unemployment insurance. The mean household income, as shown in Table 3 , was CA $\$ 43,650$ (SD: \$38,179). Regarding needsrelated factors, the three most reported mental disorders in the 12 months pre-interview were major depressive episodes (52\%), alcohol dependence (24\%) and social phobia (20\%). The mean score for psychological distress was 15.7 (SD: 7.8), and the mean number of mental disorders per subject, 1.47 (SD: 0.83).

\section{Health-service utilisation}

Among the 406 participants who experienced at least one episode of mental disorder in the 12 months prior to the interview, 212 (52\%) reported using health-care services for mental health reasons at least once. These 212 participants were beset mainly by major depressive episodes $(\mathrm{N}=129 ; 61 \%)$. The mean number of health-care services 
Table 2 Frequency distribution of participants with mental disorders in the 12 months pre-interview ( $N=406$; data weighted as to age and gender)

\begin{tabular}{|c|c|c|c|c|}
\hline & & & $\mathrm{n}$ & $\%$ \\
\hline \multirow[t]{22}{*}{ Predisposing factors } & Gender & Female & 229 & $\overline{56.4}$ \\
\hline & & Male & 177 & 43.6 \\
\hline & Age categories [n (\%)] & $15-24$ years & 70 & 17.2 \\
\hline & & $25-34$ years & 91 & 22.3 \\
\hline & & $35-44$ years & 92 & 22.7 \\
\hline & & $45-54$ years & 91 & 22.3 \\
\hline & & $55-69$ years & 63 & 15.4 \\
\hline & Education & Less than secondary school graduation & 78 & 19.1 \\
\hline & & $\begin{array}{l}\text { Secondary school graduation, no post-secondary } \\
\text { education }\end{array}$ & 60 & 14.8 \\
\hline & & Some post-secondary education & 43 & 10.7 \\
\hline & & Post-secondary degree/diploma & 225 & 55.4 \\
\hline & Marital status & Never legally married (single) & 207 & $\overline{51.1}$ \\
\hline & & Legally married (and not separated) & 66 & 16.1 \\
\hline & & Separated (but still married) & 15 & 3.8 \\
\hline & & Common-law & 58 & 14.4 \\
\hline & & Divorced & 49 & 12.0 \\
\hline & & Widowed & 11 & 2.6 \\
\hline & Place of birth & Canada & 329 & 81.0 \\
\hline & & Other & 68 & 15.1 \\
\hline & First language & French & 263 & 64.8 \\
\hline & & English & 135 & 33.2 \\
\hline & & Other & 8 & 2.0 \\
\hline \multirow[t]{5}{*}{ Enabling factors } & Main source of income & Salary & 183 & 45.1 \\
\hline & & Social welfare & 52 & 12.8 \\
\hline & & Rent or retirement pension & 19 & 4.7 \\
\hline & & Unemployment insurance & 11 & 2.7 \\
\hline & & Other & 17 & 4.1 \\
\hline \multirow[t]{10}{*}{ Needs-related factors } & $\begin{array}{l}\text { Type of mental disorder in the } 12 \text { months pre- } \\
\text { interview }\end{array}$ & Major depressive disorder & 209 & $\overline{51.5}$ \\
\hline & & Dependence & & \\
\hline & & Alcohol dependence & 97 & 23.9 \\
\hline & & Drug dependence & 77 & 19.0 \\
\hline & & Anxiety disorders & & \\
\hline & & Social phobia & 80 & 19.7 \\
\hline & & Panic disorder & 44 & 10.8 \\
\hline & & Agoraphobia & 29 & 7.1 \\
\hline & & Mania & 45 & 11.1 \\
\hline & & PTSD & 18 & 4.4 \\
\hline $\begin{array}{l}\text { Health-service } \\
\text { utilisation }\end{array}$ & Participants who have used health-care services & & 212 & 52.2 \\
\hline
\end{tabular}

used per subject in the same period was 1.9 (SD: 1.4). A majority of the participants $(\mathrm{N}=111 ; 52 \%)$ used both primary and specialised mental health-care, as against $27 \%$ $(\mathrm{N}=57)$ who used only primary care and $21 \%(\mathrm{~N}=44)$ only specialised care. The professionals most often consulted by the 212 participants for mental health reasons were general practitioners $(\mathrm{N}=134 ; 63 \%)$, psychiatrists $(\mathrm{N}=122 ; 58 \%)$ and psychologists $(\mathrm{N}=68 ; 32 \%)$. The majority of participants who sought help from psychologists $(\mathrm{N}=39 / 68 ; 63 \%)$ had private health insurance. Forty people (19\%) consulted four different types of professionals or more.

Mental health user profiles: cluster analysis

Among the 406 participants, 222 (53\%) were automatically clustered in four subgroups (Table 4), as regards 
Table 3 Descriptive statistics of participants with mental disorders in the 12 months pre-interview ( $N=406$; data weighted as to age and gender)

\begin{tabular}{|c|c|c|c|c|c|}
\hline & & Minimum & Maximum & Mean & SD \\
\hline \multirow[t]{2}{*}{ Predisposing factors } & Age & 16 & 69 & 39.40 & 13.11 \\
\hline & Household size & 1 & 7 & 2.00 & 1,18 \\
\hline Enabling factors & Total household income & 0 & 228,000 & $43,650.03$ & $38,179.43$ \\
\hline \multirow[t]{2}{*}{ Needs-related factors } & Psychological distress score & 1.00 & 37.00 & 15.6755 & 7.75732 \\
\hline & Number of mental health disorders per subject & 1 & 6 & 1.47 & 0.683 \\
\hline Health-service utilisation & Number of health-care services used in the 12 previous months & 0.00 & 8.00 & 1.8715 & 1.38426 \\
\hline
\end{tabular}

Table 4 Cluster analysis of participants according to socio-demographic characteristics, mental health disorder, and health-care service utilisation ( $N=222$; data weighted as to age and gender)

\begin{tabular}{|c|c|c|c|c|c|c|}
\hline & Variables & & & Clusters & & \\
\hline & & $\begin{array}{c}1[\mathrm{~N}=57 \\
(25.7 \%)]\end{array}$ & $2[\mathrm{~N}=45(20.3 \%)]$ & $3[\mathrm{~N}=73(32.9 \%)]$ & $4[N=47(21.2 \%)]$ & $\begin{array}{c}\text { Combined } \\
{[N=222} \\
(100 \%)]\end{array}$ \\
\hline \multirow{9}{*}{$\begin{array}{l}\text { Socio-demographic } \\
\text { characteristics }\end{array}$} & Male [n (\%)] & $6(9.1)$ & $17(25.8)$ & $20(30.3)$ & $23(34.8)$ & $66(100)$ \\
\hline & Female [n (\%)] & $51(32.7)$ & $28(17.9)$ & $53(34.0)$ & $24(15.4)$ & $156(100)$ \\
\hline & $\begin{array}{l}\text { Age categories [n } \\
(\%)]\end{array}$ & & & & & \\
\hline & 15-24 years & $0(0)$ & $13(59.1)$ & $0(0)$ & $9(40.9)$ & $22(100)$ \\
\hline & 25-34 years & $18(40.0)$ & 7 (15.6) & $10(22.2)$ & $10(22.2)$ & $45(100)$ \\
\hline & $35-44$ years & $20(29.9)$ & $17(25.4)$ & $18(26.9)$ & $12(17.9)$ & $67(100)$ \\
\hline & $45-54$ years & $11(19.6)$ & $6(10.7)$ & $29(51.8)$ & $10(17.9)$ & $56(100)$ \\
\hline & 55-69 years & $8(25.0)$ & $2(6.3)$ & $16(50.0)$ & $6(18.8)$ & $32(100)$ \\
\hline & $\begin{array}{l}\text { Household income } \\
\text { [mean (SD)] }\end{array}$ & $\begin{array}{c}37,408.50 \\
(37,070.10) \\
\end{array}$ & $27,486.10(23,895.20)$ & 47,359.00 (42,396.70) & $\begin{array}{c}30,869.70 \\
(34,131.60) \\
\end{array}$ & $\begin{array}{r}37,284.90 \\
(36,766.90) \\
\end{array}$ \\
\hline \multirow{7}{*}{$\begin{array}{l}\text { Mental health } \\
\text { disorders in the } 12 \\
\text { previous months }\end{array}$} & $\begin{array}{l}\text { Psychological distress } \\
\text { score [mean (SD)] }\end{array}$ & $16.8(7.9)$ & $19.1(7.3)$ & $15.3(7.9)$ & $13.9(7.3)$ & $16.2(7.8)$ \\
\hline & $\begin{array}{l}\text { Alcohol dependence } \\
\text { [n (\%)] }\end{array}$ & $1(2.3)$ & $15(34.9)$ & $0(0)$ & $27(62.8)$ & $43(100)$ \\
\hline & $\begin{array}{l}\text { Drug dependences } \\
{[n(\%)]}\end{array}$ & $0(0)$ & $19(52.8)$ & $0(0)$ & $17(47.2)$ & $36(100)$ \\
\hline & $\begin{array}{l}\text { Anxiety (panic } \\
\text { disorder, } \\
\text { agoraphobia, social } \\
\text { phobia) [n (\%)] }\end{array}$ & $57(77.0)$ & $17(23.0)$ & $0(0)$ & $0(0)$ & $74(100)$ \\
\hline & $\begin{array}{l}\text { Major depressive } \\
\text { disorder [n (\%)] }\end{array}$ & $28(20.9)$ & $33(24.6)$ & $73(54.5)$ & $0(0)$ & $134(100)$ \\
\hline & Mania [n (\%)] & $0(0)$ & $24(100)$ & $0(0)$ & $0(0)$ & $24(100)$ \\
\hline & $\begin{array}{c}\text { Number of mental } \\
\text { disorders per subject } \\
\text { [mean (SD)] }\end{array}$ & $1.7(0.7)$ & $2.6(1.1)$ & $1.0(0.1)$ & $1.1(0.2)$ & $1.5(0.8)$ \\
\hline $\begin{array}{l}\text { Health-care service } \\
\text { utilisation in the } 12 \\
\text { previous months }\end{array}$ & $\begin{array}{l}\text { Number of health } \\
\text { services used [mean } \\
\text { (SD)] }\end{array}$ & $2.6(2.1)$ & $3.0(2.2)$ & $2.4(1.6)$ & $2.1(1.9)$ & $2.5(1.9)$ \\
\hline Label & & $\begin{array}{c}\text { Young } \\
\text { females with } \\
\text { anxiety } \\
\text { disorders }\end{array}$ & $\begin{array}{l}\text { Young low-income earners } \\
\text { with multiple mental and } \\
\text { dependence disorders }\end{array}$ & $\begin{array}{l}\text { Middle-aged, high- } \\
\text { income females with } \\
\text { depressive disorders }\end{array}$ & $\begin{array}{l}\text { Young low-income } \\
\text { earners with } \\
\text { dependence } \\
\text { disorders }\end{array}$ & \\
\hline
\end{tabular}


their socio-demographic characteristics, mental health status, and health-service utilisation.

Cluster 1 comprised 57 users out of 222 (26\%), predominantly persons between 25 and 44 years of age (38/57 or $67 \%)$. The prototypical member $(51 / 57$ or $89 \%)$ was a female affected by anxiety disorders (panic disorder, agoraphobia, social phobia). Half also experienced a major depressive episode in the previous 12-month period. Only one member of this cluster was affected by alcohol dependence and none by drug dependence or mania. This cluster ranked second with respect to household income, psychological distress score, number of mental disorders per subject, and number of healthcare services used. It ranked third as to proportion of people with major depressive episodes. Participants in this cluster may be characterised as 'Young females with anxiety disorders'.

Cluster 2 comprised 45 users (20\% of the sample) and included a majority of younger participants (15-24 years) $(13 / 22$ or $59 \%)$. Males were over-represented in this cluster $(17 / 45$ or $38 \%$ vs. $66 / 222$ or $30 \%$ for the sample as a whole). The prototypical member of Cluster 2 was more frequently beset with mental disorder than all other users, with a mean of 2.6 per subject. This cluster encompassed all cases of mania, the greatest proportion of drug dependence, and the highest mean psychological distress score. It ranked second with regard to the proportion of alcohol dependence and anxiety disorders. It ranked first for the mean number of health-care services used. Finally, participants in this cluster reported the lowest household income. They may be referred to as 'Young low-income earners with multiple mental and dependence disorders'.

Cluster 3 comprised 73 users (33\% of the sample) who were predominantly older (45/73 or $62 \%$ ) (45-69 years). The prototypical member of this cluster was a female $(53 / 73$ or $73 \%)$ with elevated household income and affected exclusively by major depressive disorder. None was diagnosed in the last 12 months with mania, anxiety, drug or alcohol dependence. This cluster ranked third as to psychological distress and number of healthcare services used, and fourth with regard to the number of mental disorders per subject. Participants in this cluster may be characterised as 'Middle-aged high-earning females with depressive disorders'.

Finally, Cluster 4 comprised 47 users (21\% of the sample). This cluster featured the most evenly distributed age categories. It was also the only one where males (49\%) and females (51\%) were almost equally represented. The prototypical member of this cluster was a person affected predominantly by alcohol and/or drug dependence but not by anxiety or mood disorders. Cluster 4 ranked third as to household income and number of mental disorders per subject. It ranked fourth with respect to the number of health-care services used and psychological distress. Participants in this cluster may be called 'Young low-income earners with dependence disorders'.

\section{Discussion}

The study was designed to develop a typology of individuals, diagnosed with mental disorder during a 12month period, based on individual characteristics and use of services. Its purpose is to generate knowledge on service needs profiling in support of efforts to facilitate mental health-care service planning. Mean prevalence of mental disorder in the last 12 months was $17 \%$. According to epidemiological studies, the prevalence of mental disorder varies widely from country to country. In the International Consortium in Psychiatric Survey (ICPE), which focused on seven countries, the overall prevalence at 12 months was $29 \%$ in USA and $20 \%$ in Canada, as against $8 \%$ for Turkey [43]. In a recent study based of a sample of more than 21,000 adults representative of the overall population in six European countries, Alonso and Lépine [51] estimated the proportion of people affected by a mental disorder in the 12 previous months to be $11.5 \%$. More recently, a meta-analysis of 27 studies estimated at $27 \%$ the proportion of European adults with at least one mental disorder in the 12 previous months [52]. Differences in survey methods or instruments may account in part for these considerable variations $[5,51,53]$. Some disorders (e.g. bipolar disorders and drug dependence in Western European countries) were not assessed in all the surveys [53]. A greater reluctance toward participation or admission of mental illness in some countries and/or interviewer error are other possible biases that can explain the under- or over-estimation of the prevalence of mental disorders $[53,54]$.

In our study, almost $50 \%$ of persons affected in the last 12 months by a mental disorder used health-care services for mental health reasons. In comparison to other studies, this number is high. According to the 2002 Canadian Community Health Survey Mental Health and Well-Being (CCHS 1.2), only 38.5\% of Canadians used services for mental health reasons, when at least one mental disorder was present [55]. In the 1997 Australian National Survey of Mental Health and Well-Being, only 35\% of people with at least one mental disorder sought professional help [56]. In our study, the proximity of a psychiatric hospital may account for the more assiduous use of mental healthcare services. Globally, studies demonstrate that health-care services are underused by individuals with mental disorder. In Quebec and the rest of Canada, where public services are focused on the treatment of serious mental disorders and since psychological 
services are only partially available in the public health-care system, access to treatment for people with less severe disorders and without private insurance and/or with low income is limited. These situations explain in part the underutilisation of services for mental health reasons.

In our study, individuals who used services for mental health reasons received two services, on average, mainly from primary and specialised care providers, and close to $20 \%$ consulted at least four mental health-care professionals. The use of diverse and increasingly communitybased professionals is perceived as a positive development by various authors $[57,58]$. Individuals who receive dual-modality treatment (e.g. psychopharmacology and psychotherapy) are less likely to abandon treatment than people who consult psychiatrists only [58]. However, individuals with low income do not have easy access to psychologists (a service that often requires private insurance). A recent study has shown that cost is the main obstacle to psychotherapy access, especially for people with anxiety disorders [59].

Cluster analysis yielded four user profiles including people with mainly anxiety disorders (Cluster 1 ), depressive disorders (Cluster 3), alcohol and/or drug disorders (Cluster 4), and multiple mental and dependence disorders (Cluster 2).

Two clusters (1 and 3) were more closely associated with females. In the other clusters (2 and 4$)$, males were over-represented in comparison with the sample as a whole. It is interesting to note that these two clusters (where males are a majority) are linked to dependence disorders, regardless of association with mental disorders. The socio-demographic variables associated with the various clusters were consistent with previous studies on the prevalence and correlates of anxiety, mood, and dependence disorders in the general population. Our results show that anxiety [1] and depressive disorders [6] are more prevalent among females, and dependence disorders, principally alcohol dependence, and concurrent disorders more common among males [3].

In three clusters, users aged 34 years or less were over-represented. Young adulthood is a critical life stage at which people leave the family home and may make far-reaching decisions with respect to education, career or parenthood [60]. Generally, mental disorders begin during this period [7]. Most general population surveys have found a marked prevalence of mental disorder in young adulthood. For example, in the National Comorbidity Survey Replication study (NCS-R), three-quarters of lifetime mental disorders emerged by age 24 [60]. Youth is also associated with a greater risk of hospital readmission [13,61]. Conversely, age is a protective factor, with the risk of mental disorder decreasing as one gets older [62].
Age of onset may account for the differences between Clusters 1 and 3 . Cluster 1 included young women with anxiety disorders for the most part, though one half did experience a major depressive disorder. Conversely, Cluster 3 includes mainly middle-aged women who had only one major depressive episode without anxiety disorder in the last 12 months. It is possible that users in Cluster 3 successfully negotiated young adulthood and entered the job market or started a family without experiencing anxiety disorder or were successfully treated for it. Another explanation is that the major depressive episode occurred recently. If anxiety disorder tends to occur among younger individuals, mood disorder (including major depressive episodes) tends to occur among older individuals [63]. According to one study [6], lifetime rates and the probability of major depressive disorder are higher among baby-boomers than younger adults.

Co-morbidity with mental disorder appears to be the norm $[64,65]$. In three of four clusters, users were affected by more than one mental or dependence disorder. In Cluster 2, co-morbidity with mood disorder, anxiety, and dependence disorder was very frequent. Several studies indicate a significant correlation between alcohol dependence and depression [66-68]. Intoxication by alcohol or drugs can induce symptoms similar to those of depressive disorder [66]. Some drugs can increase stress and provoke panic attacks or other anxiety disorders [4]. It is also known than several people with anxiety or mood disorder use alcohol or drugs as self-medication [69]. Users with dual diagnoses present a challenge for mental health and addiction services and generally have worse treatment outcomes [64,67]. Comorbid disorders are generally more chronic than pure mental disorders, and treatment is less effective [4]. Cluster 4 was distinguished from Cluster 2 by the absence of mania, major depressive episodes, and anxiety. Cluster 4 was characterised by dependence disorder, combined with more marginal mental disorder, and exhibited a propensity for alcohol, rather than drug, use. Several studies have revealed that alcohol dependence is generally not as strongly associated with mental disorder as is drug dependence $[64,67,70,71]$.

Clusters 1 and 2 were the most keenly affected by psychological distress. Conversely, Cluster 4, which encompassed only 1.1 mental or dependence disorders per subject, was not as greatly impacted by psychological distress as other clusters. These results seem to confirm that the number of mental disorders is associated with greater psychological distress [64]. We may assume that multiple mental or dependence disorders can affect several domains essential to quality of life (work, daytime activities, social and intimate relationships, physical health, etc.). 
Finally, Clusters 1 and 2 featured the greatest number of mental disorders per subject and the most frequent use of mental health-care services. According to several studies, needs factors are the prime predictors of service use $[9,72,73]$, and greater numbers of mental disorders result in more frequent use of healthcare services [64]. In addition, some authors have suggested that users with multiple mental and dependence disorders feel a greater impetus to seek treatment $[64,74]$. However, it is interesting to note that the mean number of health-care services used by Cluster 3, with only one mental disorder, is quite similar to that of Cluster 1 . One possible explanation is that participants in Cluster 3, with the highest household income, make more frequent use of private psychologists to treat major depressive disorders. For Vasiliadis and colleagues, depression is the most significant predictor of service use [20]. Gender may also account for similarities between Clusters 1 and 3 regarding service utilisation. It is known that females use more health-care services in general, mainly general practitioners and other primary care services. Age may also explain the differences: middle-aged persons are the peak users of mental health-care services [75]. Conversely, younger people are less likely to perceive their need for treatment and often wish to solve problems on their own [32]. Young adults are also more likely to drop out of treatment [58]. Finally, participants in Cluster 4 use relatively few health-care services. This is the case for people affected only by substance disorders [33]. They are usually less likely to think they need help than participants with comorbid mental disorders [74].

This study has some limitations. First, information was not available on participants' physical condition. Several epidemiological studies have reported that people with mental health disorders or dependence disorders often also have significant physical disorders, such as hypertension, diabetes or epilepsy [76,77]. The presence of a physical disease may account for more frequent use of health-care services. Second, our study did not include the full spectrum of psychiatric disorders, e.g. schizophrenia and other serious mental disorders, organic mental disorders, sexual disorders, eating disorders, personality disorders, and intellectual deficiencies. Several studies have reported a prevalence of personality disorders with anxiety, depression or substance-use disorders. Near half the people with a current mood or anxiety disorder have at least one personality disorder [78]; identifying these disorders would have allowed us to refine our cluster analysis. Finally, the severity of mental disorder was not considered. Previous studies have reported that severe cases use more services than mildly severe or moderate ones [33].

\section{Conclusion}

The study found considerable heterogeneity among sociodemographic characteristics, number of disorders, and number of health-care services used by individuals with mental or dependence disorders. Overall, there is significant underutilisation of mental health-care services with female consuming more services than men. When individuals sought services for mental health reasons, they generally saw more than one provider and used both primary and specialised mental health-care. As services are underutilised and mental disorders vary with regard to gender, age, and other characteristics, it is crucial to develop treatment modes or service programs that target specific mental disorder profiles. Our study reveals the existence of four subgroups of users with mental disorders: 'young females with anxiety disorders'; 'young low-income earners with multiple mental and dependence disorders'; 'middleaged, high-income females with depressive disorders'; and 'young low-income earners with dependence disorders'. The second group exhibited the most socio-economic vulnerability and most frequent service utilisation.

Along with the need to target the four subgroups above with specific programs, our study highlights the relevance of focusing on younger individuals affected by multiple mental disorders or anxiety disorders concurrent with or without major depressive disorders. As concomitant problems are frequent among people with mental disorders, psychological services and/or addiction programs must also be taken into consideration as components of integrated programs or shared-care initiatives when planning treatment. In addition, as males seem to consult only when they suffer multiple mental and substance disorders, more outreach and promotion programs are needed to detect and facilitate mental health-care service access for them. Globally, public education on drug use and mental disorders and programs specially designed for youths and/or males may reduce this clientele's reticence to use health-care services. Integrating motivational and cognitive aspects of behavioural change in professional training may also lead to greater mental health-care utilisation. At last, enabling greater collaboration within the health-care system between professionals (including general practitioners) and programs, especially with regard to mental disorders and substance abuse, should lead to more timely and appropriate care.

\section{Acknowledgements}

The study was funded by the Canadian Institute of Health Research (CIHR). We would like to thank this grant agency and all the individuals who participated in the research.

\section{Author details}

'Department of Psychiatry, McGill University, 845 Sherbrooke Street West, Montreal, Quebec, Canada, H3A 2T5. ²Douglas Hospital Research Centre, 6875 LaSalle Boulevard Montreal, Quebec, H4H 1R3, Canada. 


\section{Authors' contributions}

MJF, GG and MP designed the study. JMB carried out the statistic analyses with assistance from JC. MJF and GG wrote the article. All authors have read and approved the final manuscript.

\section{Competing interests}

The authors declare that they have no competing interests.

Received: 23 November 2010 Accepted: 20 April 2011 Published: 20 April 2011

\section{References}

1. Somers JM, Goldner EM, Waraich P, Hsu L: Prevalence and incidence studies of anxiety disorders: a systematic review of the literature. Can Psychiatry 2006, 51:100-113.

2. Waraich P, Goldner EM, Somers JM, Hsu L: Prevalence and incidence studies of mood disorders: A systematic review of the literature. Can J Psychiatry 2004, 49:124-138.

3. Somers JM, Goldner EM, Waraich P. Hsu L: Prevalence studies of substance-related disorders: a systematic review of the literature. Can $J$ Psychiatry 2004, 49:373-384

4. Kessler RC: The epidemiology of dual diagnosis. Biol Psychiatry 2004, 56:730-737.

5. Pirkola SP, Isometsä E, Suvisaari J, Aro H, Joukamaa M, Poikolianen K Koskinen S, Aromaa A, Lönnquvist JK: DSM-IV mood-, anxiety- and alcohol use disorders and their comorbidity in the Finnish general population. Result from the Health 2000 Study. Soc Psychiatry Psychiatr Epidemiol 2005, 40:1-10.

6. Hasin DS, Goodwin RD, Stinson FS, Grant BF: Epidemiology of major depressive disorder. Results from the National Epidemiologic Survey on alcoholism and related conditions. Arch Gen Psychiatry 2005, 62:1097-1106.

7. Jacobi F, Wittchen HU, Hölting C, Höfler M, Pfister H, Müller N, Lieb R: Prevalence, co-morbidity and correlates of mental disorders in the general population: results from the German Health Interview and Examination Survey (GHS). Psychol Med 2004, 34:597-611.

8. Medina-Mora ME, Borges G, Lara C, Benjet C, Blanco J, Fleiz C, Villatoro J, Rojas E, Zambrano J: Prevalence, service use, and demographic correlates of 12-month DSM-IV psychiatric disorders in Mexico: results form the Mexican National Comorbidity Survey. Psychol Med 2005, 35:1773-1783.

9. Andersen RM: Revisiting the Behavioral Model and Access to Medical Care: Does It Matter? J Health Soc Behav 1995, 36:1-10.

10. Leaf PJ, Livingston MM, Tischler GL, Weissman MM, Holzer CE, Myers JK: Contact with health professionals for the treatment of psychiatric and emotional problems. Med Care 1985, 23:1322-1337.

11. Narrow WE, Regier DA, Norquist G, Rae DS, Kennedy C, Arons B: Mental health service use by Americans with severe mental illness. Soc Psychiatry Psychiatr Epidemiol 2000, 35:147-155.

12. Dhingra SS, Zack M, Strine T, Pearson WS, Balluz L: Determining prevalence and correlates of psychiatric treatment with Andersen's Behavorial Model of Health Services Use. Psychiatr Serv 2010, 61:514-528.

13. Carr VJ, Johnston PJ, Lewin TJ, Rajkumar S, Carter GL, Issakidis C: Patterns of service use among persons with schizophrenia and other psychotic disorders. Psychiatr Serv 2003, 54:226-235.

14. Vasiliadis HM, Lesage A, Adair C, Boyer R: Service use for mental health raisons: Cross-provincial difference in rates, determinants, and equity of access. Can J Psychiatry 2005, 50:614-619.

15. Wang PS, Lane M, Olfson M, Pincus HA, Wells KB, Kessler RC: Twelve-month use of mental health services in the United States. Arch Gen Psychiatry 2005, 62:629-640.

16. Uebelacker LA, Wang PS, Berglund P, Kessler RC: Clinical differences among patients treated for mental health problems in general medical and specialty mental health settings in the National Comoribidity Survey Replication (NCS-R). Gen Hosp Psychiatry 2006, 28:387-395.

17. Wells KB, Manning WG, Duan N, Newhouse JP, Ware JE Jr: Sociodemographic factors and the use of outpatient mental health services. Med care 1986, 24:75-85.

18. Parslow RA, Jorm AF: Who uses mental health services in Australia? An analysis of data from the National Survey of Mental Health and Wellbeing. Aust N Z J Psychiatry 2000, 34:997-1008.
19. Bebbington P, Meltzer H, Brugha TS, Farrell M, Jenkins R, Ceresa C, Lewis G: Unequal access and unmet need: neurotic disorders and the use of primary care services. Psychol Med 2000, 30:1359-1367.

20. Vasiliadis HM, Lesage A, Adair C, Wang PS, Kessler RC: Do Canada and the United States differ in prevalence of depression and utilization of services. Psychiatr Serv 2007, 58:63-71.

21. Keyes KM, Hatzenbuehler ML, Alberti P, Narrow WE, Grant BF, Hasin DS Service utilization differences for Axis I psychiatric and substance use disorders between white and black adults. Psychiatr Serv 2008, 59:893-901.

22. Whitley R, Kirmayer $L$, Groleau D: Understanding immigrants" reluctance to use mental health services: A qualitative study from Montreal. Can J Psychiatry 2006, 51:205-209.

23. Kirmayer L, Weinfeld M, Burgos G, du Fort GG, Lasry JC, Young A: Use of health care services for psychological distress by immigrants in an urban multicultural milieu. Can J Psychiatry 2007, 52:295-304.

24. Wang PS, Berglund P, Kessler RC: Recent care of common mental disorders in the United States: prevalence and conformance with evidence-based recommendations. J Gen Intern Med 2000, 15:284-292.

25. Hendryx MS, Ahern MM: Acess to mental health services and health sector social capital. Adm Policy Ment Health 2001, 28:205-217.

26. Alegria $M, B i j l R V$, Lin E, Walters EE, Kessler RC: Income differences in persons seeking outpatient treatment for mental disorders. Arch Gen Psychiatry 2000, 57:383-391.

27. Katerndahl DA, Realini JP: Use of health care service by persons with panic symptoms. Psychiatr Serv 1997, 48:1027-1032.

28. Goodwin R, Andersen RM: Use of the behavioral model of health care use to identify correlates of use of treatment for panic attacks in the community. Soc Psychiatry Psychiatr Epidemiol 2002, 37:212-219.

29. Kushner K, Diamond R, Beasley JW, Mundt M, Plane MB, Robbins K: Primary care physicians' experience with mental health consultation. Psychiatr Serv 2001, 52:838-840.

30. Pasic J, Russo J, Roy-Byrne P: High utilizers of psychiatric emergency services. Psychiatr Serv 2005, 56:678-684

31. Kent $\mathrm{S}$, Fogarty $\mathrm{M}$, Yellowlees $\mathrm{P}: \mathrm{A}$ review of studies of heavy users of psychiatric services. Psychiatr Serv 1995, 46:1247-1253.

32. Kessler RC, Berglund PA, Bruce ML, Koch JR, Laska EM, Leaf PJ, Mandercheid RW, Rosenheck RA, Walters EE, Wang PS: The prevalence and correlates of untreated serious mental illness. Health Serv Res 2001, 36:987-1007.

33. Tempier R, Meadows GN, Vasiliadis HM, Mosier KE, Lesage A, Stiller A, Graham A, Lepnurm M: Mental disorders and mental health care in Canada and Australia: comparative epidemiological findings. Soc Psychiatry Psychiatr Epidemiol 2009, 44:63-72.

34. Rubin WV, Panzano PC: Identifying meaningful subgroups of adults with severe mental illness. Psychiatr Serv 2002, 53:452-457.

35. Casper ES, Donaldson B: Subgroups in the population of frequent users of inpatient services. Hosp Community Psychiatry 1990, 41:189-191.

36. Fisher S, Stevens RF: Subgroups of frequent users of an inpatient mental health program at a community hospital in Canada. Psychiatr Serv 1999, 50:244-247.

37. Lora A, Cosentino U, Rossini MS, Lanzara D: A cluster anlaysis of patients with schizophrenia in community care. Psychiatr Serv 2001, 52:682-684.

38. Herman SE, Mowbray CT: Client typology based on functioning leve assessments: utility for service planning and monitoring. J Ment Health Adm 1991, 18:101-115.

39. Luke DA, Mowbray CT, Klump K, Hernman SE, BootsMiller B: Exploring the diversity of dual diagnosis: Utility of cluster analysis for program planning. J Ment Health Adm 1996, 23:298-316.

40. Guzzetta F, Miglio R, Santone G, Picardi A, Norcio B, Bracco R, De Girollamo G, Group PA: First-ever admitted psychiatric inpatients in Italy: clinical characteristics and reasons contributing to admission: findings from a national survey. Psychiatry Res 2010, 176:62-68.

41. Mitchell KJ, Finkelhor D, Becker-Blease KA: Classification of adults with problematic internet experiences: linking internet and conventional problems from a clinical perspectives. Cyberpsychol Behav 2007, 10:381-392.

42. Caron J, Tousignant M, Pedersen D, Fleury MJ, Cargo M, Daniel M, Kestin Y, Crocker A, Perreault M, Brunet A, Tremblay J, Turecky G, Beaulieu S: La création d'une nouvelle génération d'études épidémiologiques en santé mentale. Sante Ment Que 2007, 32:225-238.

43. WHO International Consortium in Psychiatric Epidemiology: Cross-national comparisons of the prevalences and correlates of mental disorders. Bull World Health Organ 2000, 78:413-426. 
44. Vega WA, B K, Aguilar-Gaziola S, Alderete E, Catalano R, Caraveo-Anduaga J: Lifetime prevalence of DSM-III-R psychiatric disorders among urban and rural Mexican Americans in California. Arch Gen Psychiatry 1998, 55:771-778.

45. Bijl RV, Ravelli A, van Zesseen G: Prevalence of psychiatric disorder in the general population: results of the Netherlands Mental Health Survey and Incidence Study (NEMESIS). Soc Psychiatry Psychiatr Epidemiol 1998, 33:587-595.

46. Kessler RC, McGonagle KA, Zhao S, Nelson CB, Hughes M, Eshleman S, Wittchen HU, Kendler KS: Lifetime and 12-month prevalence of DSM-III-R in the United States: Results form the National Comorbidity Survey. Arch Gen Psychiatry 1994, 51:8-19.

47. Skinner HA: The Drug Abuse Screening Test. Addict Behav 1982, 7:363-371.

48. Bohn MJ, Babor TF, Kranzler HR: The Alcohol Use Disorders Identification Test (AUDIT): validation of a screening instrument for use in medical settings. J Stud Alcohol 1995, 56:423-432.

49. Kessler RC, Barker PR, Colpe LJ, Epstein JF, Gfroerer JC, Hiripi E, Howes MJ, Normand SL, Mandercheid RW, Walters EE, Zalasky AM: Screening for serious mental illness in general population. Arch Gen Psychiatry 2003, 60:184-189.

50. Caron J, Liu A: A descriptive study of the prevalence of psychological distress and mental disorders in the Canadian population: comparison between low-income and non-low income populations. Chronic Dis Can 2010, 30:84-94.

51. Alonso J, Lépine JP, Committee EMS: Overview of key data from the European Study of the Epidemiology of Mental Disorders (ESEMeD). $J$ Clin Psychiatry 2007, 68:3-9.

52. Wittchen HU, Jacobi F: Size and burden of mental disorders in Europe - a critical review and appraisal of 27 studies. Eur Neuropsychopharmacol 2005, 15:357-376.

53. Kessler RC, Angermeyer MC, Anthony JC, De Graaf R, Demyttenaere K, Gasquet I, De Girolamo G, Gluzman S, Gureje O, Haro JM, kawakami N, Levinson D, Medina Mora ME, Oakley Browne MA, Posada-Villa J, Slein DJ, Aguilar-Gaxiola S, Alonso J, Heeringa S, Pennell BE, Berglund $\mathrm{P}$, Petukhova M, Chatterji S, Ustün TB: Lifetime prevalence and age-of-onset distributions of mental disorders in the World Health Organization's World Mental Health Initiative. World Psychiatry 2007, 6:168-176.

54. Demyttenaere K, Bruffaerts J, Posalada-Villa J, Gasquet I, Kovess V, Lepine JP, Angermeyer MC, Bernet S, de Girolamo G, Moriosini P, Kikkawa T, Kawakami N, Ono Y, Takeshima T, Uda H, Karam EG, Favyad JA, Karam AM, Mneimneh ZN, Medina-Mora ME, Borges G, Lara C, De Graaf R, Ormel J, Gureje O, Shen Y, H Y, Zhang M, Alonso J, Haro JM, Vilaqut G, Bromet E, Gluzman S, Webb C, Kessler RC, Merikangas KR, Anthony JC, Von Korff MR, Wang PS, Brugha TS, Aguilar-Gaxiola S, Lee S, Heeringa S, Pennell BE, Zaslavsky AM, Ustun TB, Chatterij S, WHO World Mental Health Consortium: Prevalence, severity and unmet need for treatment of mental disorders in the World Health Organization World Mental Health Surveys. JAMA 2004, 291:2581-2590.

55. Lesage A, Vasiliadis H-M, Gagné M-A, Dudgeon S, Kasman N, Hay C: Prevalence of mental illness and related service utilization in Canada: an analysis of the Canadian Community Health Survey Mississauga, Ontario; 2006.

56. Andrews G, Henderson S, Hall W: Prevalence, comorbidity, disability and service. Br J Psychiatry 2001, 178:145-153.

57. Wang PS, Demler O, Olfson M, Pincus HA, Wells KB, Kessler RC: Changing profiles of service sectors used for mental health care in the United States. Am J Psychiatry 2006, 163:1187-1198.

58. Edlund MJ, Wang PS, Berglund PA, Katz SJ, Lin E, Kessler RC: Dropping out of mental health treatment: patterns and predictors among epidemiological survey respondents in the United States and Ontario. Am J Psychiatry 2002, 159:845-851.

59. Chartier-Otis M, Perreault M, Bélanger C: Determinants of Barriers to Treatment for Anxiety Disorders. Psychiatr Q 2010, 81:127-138.

60. Suvisaari J, Aalto-Setälä T, Tuulio-Henricksson A, Härakänen T, Saarni SI, Perälä J, Schreck M, Castaneda A, Hintikka J, Kestilä L, Lähteenmäki S, Latvala A, Koskinen S, Marttunen M, Aro H, Lönnquvist J: Mental disorders in young adulthood. Psychol Med 2009, 39:287-299.

61. Oiesvold T, Saaranto O, Sytema S, Vinding H, Göstas G, Lönnerberg O, Muus S, Sandlund M, Hansson L: Predictors for readmission risk of new patients: the Nordic Comparative Study on Sectorized Psychiatry. Acta Psychiatr Scand 2000, 101:367-373.

62. Hedtke KA, Ruggiero KJ, Fitzerald MM, Zinzow HM, Saunders BE, Resnick HS, Kilpatrick DG: A longitudinal investigation of interpersonal violence in relation to mental health and substance use. J Consult Clin Psychol 2008 76:633-647.

63. Andrade L, Caraveo-Anduaga JJ, Berglund P, Bijl RV, Kessler RC, Demler O, Walters EE, Kylyc C, Offord D, Üstün TB, Wittchen HU: Cross-national comparisons of the prevalences and correlates of mental disorders. Bull World Health Organ 2000, 78:421-426.

64. Castel S, Rush BR, Urbanoski K, Toneatto T: Overlap of clusters of psychiatric symptoms among patients of a comprehensive addiction treatment service. Psychol Addict Behav 2006, 20:28-35.

65. Kessler RC, Ormel J, Petukhova M, McLaughlin KA, Green JG, Russo LJ, Stein DJ, Zaslavsky AM, Aguilar-Gaxiola S, Alonso J, Andrade L, Benjet C, De Girolamo G, De Graaf R, Demyttenaere K, Favyad J, Haro JM, Hu C, Karam A, Lee S, Lepine JP, Mihaescu-Pintia C, Posada-Villa J, Sagar R, Ustün TB: Development of lifetime comorbidity in the World Health Organization world mental health surveys. Arch Gen Psychiatry 2011, 68:90-100.

66. Hasin DS, Grant BF: Major depression in 6050 former drinkers. Arch Gen Psychiatry 2002, 59:794-800.

67. Merikangas KR, Mehta MA, Molnar BE, Aguilar-Gaziola S, Bijl RV, Borges G, Caraveo-Anduaga JJ, Dewit DJ, Kolody B, Vega WA, Wittchen HU, Kessler RC: Comorbidity of substance use disorders with mood and anxiety disorders; results of the international consortium in psychiatric epidemiology. Addict Behav 1998, 23:893-907.

68. Kessler RC, Crum RM, Warner LA, Nelson CB, Schulenberg J, Anthony JC: Lifetime co-occurrence of DSM-III-R Alcohol abuse and depedence with other psychiatric disorders in the National Comorbidity Survey. Arch Gen Psychiatry 1997, 54:313-321.

69. Carrigan $M H$, Randall CL: Self-medication in social phobia: a review of the alcohol literature. Addict Behav 2003, 28:269-284.

70. Farrell M, Howes S, Bebbington P, Brugha T, Jenkins R, Lewis G, Mardsen J, Taylor C, Meltzer H: Nicotine, alcohol and drug dependence and psychiatric comorbidity. Results of a national household survey. $\mathrm{Br} J$ Psychiatry 2001, 179:432-437.

71. Kessler RC, Nelson CB, MCGonagle KA, Edlund MJ, Frank RG, Leaf PJ: The epidemiology of co-occuring addictive and mental disorders: Implications for prevention and service utilization. Am J Orthopsychiatry 1996, 66:17-31.

72. Lefebvre J, Lesage A, Cyr M, Toupin J, Fournier L: Factors Related to Utilization of Services for Mental Health Reasons in Montreal, Canada. Soc Psychiatry Psychiatr Epidemiol 1998, 33:291-298.

73. Lin E, Goering PN, Lesage A, Streiner DL: Epidemiologic Assessment of Overmet Need in Mental Health Care. Soc Psychiatry Psychiatr Epidemiol 1997, 32:355-362.

74. Mojtabai R, Olfson M, Mechanic D: Perceived need and help-seeking in adults with mood, anxiety, or substance use disorders. Arch Gen Psychiatry 2002, 59:77-84.

75. Meadows G, Singh B, Burgess P, Bobevski I: Psychiatry and the need for mental health care in Australia: findings from the National Survey of Mental Health and Wellbeing. Aust N Z J Psychiatry 2002, 36:210-216.

76. Dickey B, Sharon-Lise N, Weiss RD, Drake RE, Azeni H: Medical morbidity, mental illness, and substance use disorders. Psychiatr Serv 2002, 53:861-867.

77. Scott KM, Bruffaerts R, Tsang A, Ormel J, Alonso J, A MC, Benjet C, Bromet E, De Girolamo G, De Graaf R, Gasquet I, Gureje O, Haro JM, Ye Y, Kessler RC, Levinson D, Mneimneh ZN, Oakley Browne MA, Posada-Villa J, Stein DJ, Takeshima T, Von Korff M: Depression-anxiety relationships with chronic physical conditions: Results form the World Mental Health surveys. J Affect Disord 2007, 103:113-120.

78. Grant BF, Hasin DS, Stinson FS, Dawson DA, Patricia Chou S, Ruan WJ, Huang B: Co-occurence of 12-month mood and anxiety disorders and personality disorders in the US: results from the national epidemiologic survey on alcohol and related conditions. J Psychiatr Res 2005, 39:1-9.

\section{Pre-publication history}

The pre-publication history for this paper can be accessed here: http://www.biomedcentral.com/1471-244X/11/67/prepub

doi:10.1186/1471-244X-11-67

Cite this article as: Fleury et al:: Typology of adults diagnosed with mental disorders based on socio-demographics and clinical and service use characteristics. BMC Psychiatry 2011 11:67. 